\title{
FOCUS
}

\section{Contemporary Thought and Practice in Cognitive Mapping Research: An Introduction}

\author{
Scott M. Freundschuh \\ Department of Geography, University of Minnesota, Duluth \\ Rob Kitchin \\ Department of Geography, National University of Ireland, Maynooth
}

\section{Introduction}

The five papers included in this theme section have their origins in a day-long symposium held at the 1997 Annual Meeting of the Association of American Geographers in Fort Worth, Texas. The focus of this symposium was cognitive mapping in its broadest interpretation, and its aim was two-fold. First, to bring together an international gathering of researchers to exchange ideas and foster research collaborations. Second, to examine recent developments, empirical research, and future directions in cognitive mapping, attempting to gain a coherent summary of cognitive mapping research as currently theorized and practiced.

The fact that this symposium was hosted and organized by geographers is not insignificant. For the past forty years, since Lynch's (1960) seminal book, The Image of the City, geographers have been examining how people think about and behave in geographic space. From the inception of this enterprise, geographers have been adept at looking beyond its disciplinary boundaries and taking the lead in trying to foster multidisciplinary research. Indeed, it was geographers who brought together representatives from ten separate disciplines at the 1965 Association of American Geographers' conference in Columbus, Ohio. This visionary event ultimately lead to the establishment of the Environmental Design and Research Association (EDRA) and to the beginning of the cross-disciplinary journal, Environment and Behavior in 1969 (Kitchin et al. 1997).

Since this time, geographers have worked hard to keep these reciprocal, multidisciplinary links strong, confident in the belief that geography often informs, and is informed by, other disciplines. There can be little doubt that the research area of behavioral geography, and in particular the study of spatial cognition, has benefited significantly from cross-disciplinary collaboration, interaction and dissemination. Examples of this cross-disciplinary work can be found in a series of edited collections: Downs and Stea (1973, 1977), Moore and Golledge (1976), Golledge and Rayner (1983), Gärling and Evans (1991) and Gärling and Golledge (1993). In the 1990s, geographers have been instrumental in continuing to encourage collaboration across the disciplines through the work of the National Center for Geographic Information and Analysis (NCGIA). During the ten years of the NCGIA's existence, the Center has sponsored and funded cross-disciplinary research through its many research initiatives. Examples of these initiatives include Languages of Spatial Relations, Spatio-Temporal Reasoning in GIS, Multiple Representations, User-Interfaces for GIS, Formal Models of CommonSense Geographic Worlds, Formalizing Cartographic Knowledge, Scale and Detail in the Cognition of Geographic Space, Cognitive Models of Dynamic Geographic Phenomena and Representations, and Multiple Modalities and Multiple Reference Frames for Spatial Knowledge. These research initiatives have brought together scientists from Psychology (cognitive, developmental, environmental), Linguistics, Computer Science, Cognitive Science, Philosophy, Information Science, Survey Engineering, and Geography in a forum that 
produces research agendas for each of the initiative topics. It is a truly interdisciplinary endeavor. This theme section continues the tradition of encouraging geographers and other disciplines to learn from one another.

\section{Symposium}

The symposium consisted of 27 papers divided into five sessions, plus a plenary panel session. The papers that were presented detailed a wide range of empirical studies and addressed a number of substantive theoretical issues across a spectrum of the following topical areas: Spatial Abilities, Disabilities, Development, Representation, Image and Narrative Learning, Route Learning, Wayfinding, Environmental Learning, Virtual Worlds.

Session participants were invited to give papers on current research and theory in cognitive mapping, highlighting the multidisciplinary nature of the field and the unique opportunities that we have for cross-disciplinary research. The varied disciplinary backgrounds of the participants reflect the multidisciplinary (and hopefully interdisciplinary) nature of cognitive mapping research. Participants included behavioral and cognitive geographers, developmental and cognitive psychologists, and computer, cognitive and information scientists. The five papers included in this theme issue have been chosen as a representative sample of the wider set of papers presented in Fort Worth. As a collection, they are valuable because they illustrate the latest thinking in a field that is increasingly becoming an interdisciplinary endeavor and one in which geographers play a central role.

\section{An Overview of Papers}

The first two papers, the first by Blaut, and the second by Tversky et al., concern issues of how people conceptualize space. The papers offer two different perspectives on aspects of human conceptions of space, highlighting the contrast between the views from psychology and geography, as well as the common ground between these two views. Blaut, in his paper "Maps and Space," explores the dichotomy between the structure of space versus the content of space. Blaut contends that "space" can mean different things to environmental psychology and geography. Geographers typically consider space as the size of the geographical places and their associated processes. In other words, space is a macro-environment that exists in space-time, having complex processes and meaning. In comparison, psychologists often are concerned with space as form or structure, pure space, space as geometry. Blaut explores the contradictions between these two views of space, positing that "our ideas of pure space are distilled from our space-time experience, by the use of our powers of imagination, or by abstraction" (p. 511). Blaut then leads us through a series of flaws in the interpretation of empirical studies that arise when these two notions of space are confused.

In the paper by Tversky, Morrison, Franklin, and Bryant, the authors review a growing body of empirical research that offers evidence for "Three Spaces of Spatial Cognition." This paper focuses on the structure of space, and how this structure is reflected in the ways we interact with and conceptualize the world. The authors partition space into the space of navigation, the space around the body and the space of the body. The space of navigation is schematized "in terms of elements, reference frames and perspectives (p. 518)." Elements include environmental features and the spatial relations between them. These elements have been schematized as nodes, links, boundaries, edges, regions, enclosures, landmarks, and paths between landmarks. Elements are experienced from many different perspectives from multiple sources. These various perspectives, or views, are linked by a common reference frame, such as cardinal directions or a significant landmark. The Spatial Framework Model explains space around the body. The spatial framework model consists of the three major axes of the body: head/feet (up/down), front/back (in front/behind), and left/right. Of the three axes, head/feet is the most salient, front/back is the next most salient, and left/right is the least salient. The space of the body is best explained by the part significance theory. Part significance theory integrates information about bodily sensations, actions and appearance. The space of the body relies on function, appearance, sensation, action and visual salience, with a bias toward parts with greater salience defined by contour discontinuity for visual situations, and bias toward parts with greater significance when function or action is aroused. The basis for this division of space is research that has explored the way humans perceive and interact with the spaces. 
The next two papers by Lloyd and by Blades and his colleagues explore the acquisition of spatial information from multiple information sources experienced through multiple modalities. The result of their work is a measure of the efficacy of these sources for conveying spatial information to the user. In "Organization of Feature-, Time-, or Location-Based Mental Models," Lloyd compares the encoding of spatial, temporal, and entity information displayed on maps into memory. Lloyd conducted an empirical study that required participants to encode information from (1) text, correlating people with the state where they lived, (2) maps, correlating time with symbol type, (3) maps, correlating location with symbol type, and (4) maps, correlating time with location. The results of Lloyd's study have important implications for designers of maps in general, and for map animations specifically. The results suggest that common "frame based" animations may not be the most effective way to present temporal information to the map user.

In "Map Using by Adults with Visual Impairments," Blades, Ungar, and Spencer explore the efficacy of tactile maps to augment the cognitive maps of people with visual impairments. The authors describe a series of empirical studies that required visually impaired subjects to learn a route via a tactile map, direct experience, direct experience with a tactile map, and direct experience with verbal directions. They also describe two studies that compare spatial knowledge acquisition of sighted and visually impaired subjects from maps, lists, and verbal descriptions, and then from maps with a name template, maps with a road template, and maps with an area template. The authors discuss the advantages of tactile maps as sources of spatial information for visually impaired map users, and the importance of training so that visually impaired people can use these navigation aids effectively.

The last paper in this theme issue by Allen focuses on spatial abilities as they relate to wayfinding skills. Allen weaves together wayfinding tasks and the methods used for successfully carrying out these tasks as a means for examining spatial-cognitive abilities. In "Cognitive Abilities in the Service of Wayfinding: A Functional Approach," Allen suggests that a functional approach to wayfinding research is valid for both psychology and geography. He indicates that this approach "focuses on the purpose of the task at hand as well as on the adaptive significance of the abilities applied to meet the demands of that task" (p. 554). Allen provides a conceptual framework for relating cognitive abilities to different types of wayfinding tasks that can be used as a basis for developing standardized assessments (tasks) that validate the various constructs.

\section{Concluding Statement}

The papers presented in this theme section provide a small sample of the latest in contemporary thought and practice in cognitive mapping research. As they illustrate, cognitive mapping has developed into a rich multidisciplinary field, with a range of topical interests, in which geography is a key component. Through collaboration and synthesis, cognitive mapping research has developed to provide insights into a number of key theoretical issues concerning how we learn, comprehend and behave in geographic space. This body of research also provides the keystones for real-world "spatial" applications, such as the development of search-and-rescue technologies, map design, implementation and use of geographic information systems, the design of geography education curriculums, and the development of mobility and navigation aids for visually impaired people (see Jackson and Kitchin 1998). The papers presented here demonstrate the continued inter-disciplinary work in spatial cognition research, present several new links between psychologists and geographers, and illustrates the benefits of multi-disciplinary research in cognitive mapping for the development and design of the ever broadening array of spatial information tools.

\section{References}

Downs, Roger M., and David Stea, eds. 1973. Image and Environment: Cognitive Mapping and Spatial Behavior. Chicago: Aldine.

Downs, Roger M., and David Stea. 1977. Maps in Minds: Reflections on Cognitive Mapping. New York: Harper and Row.

Gärling, T., and Evans, G.W., eds. 1991. Environment, Cognition and Action-An integrated approach. New York: Oxford University Press.

Gärling, Tommy, and Reginald G. Golledge, eds. 1993. Behavior and Environment: Psychological and Geographical approaches. London: North Holland. 
Golledge, R.G., and J.N. Rayner. 1982. Proximity and Preference. Minneapolis: University of Minnesota Press.

Jackson, P., and R.M. Kitchin, eds. 1998. Applying Cognitive Mapping. Fournal of Environmental Psychology 18:219-339.

Kitchin, R.M., M. Blades, and R.G. Golledge. 1997. Relations between psychology and geography. Environment and Behavior 29(4):554-573.

Lynch, Kevin. 1960. The Image of the City. Cambridge: MIT Press.

Moore, Gary T., and Reginald G. Golledge, eds. 1976. Environmental Knowing. Stroudsberg, PA: Dowden, Hutchinson and Ross.
SCOTT FREUNDSCHUH is an Associate Professor at the University of Minnesota, Duluth, Duluth, MN 55812. His research interests focus on spatial cognition in children and adults, with particular interests in the understanding and use of locatives, spatial knowledge acquired from maps, from the environment, and from narrative, and the influence that pattern or structure of the environment has on spatial knowledge acquisition.

ROB KITCHIN is a Lecturer in Human Geography at the National University of Ireland, Maynooth. His research interests focus on social and cultural geography, with particular interests in geographies of disability, geographies of violence, geographies of cyberspace and cognitive geography. 